\title{
NOTES ON THE TEXT
}

1. For transliteration of Korean words, I will consistently use the official Korean-language romanization system released by South Korea's Ministry of Culture and Tourism in 2000, also referred to as Revised Romanization of Korean. Exceptions are made for proper names well known in the English-speaking world by alternate romanizations (e.g., Park Chung-hee rather than Bak Jeong-hui); for authors who have published their names in alternate romanizations (e.g., Kim Suk-Young rather than Gim Suk-yeong); and for performers who deliberately use alternate romanizations for their names (e.g., Lee Hi rather than Yi Ha-i). In the case of these exceptions, the Official Romanization of Korean appears in parentheses after the first occurrence of the term.

2. For East Asian names, surnames precede given names according to the convention of the home country; hence East Asian names appear with the surname first (e.g., Lee Su-man, not Su-man Lee; Ueno Toshiya, not Toshiya Ueno).

3. For the combination of Anglicized first names and Korean last names, the first and the second rules do not apply (e.g., Edward Kang rather than Gang Edward).

4. K-pop band names like BIGBANG or SHINee are mostly left in their own Anglicized spellings, since the groups deliberately use idiosyncratic spellings for professional purposes and are known as such in both Korean and international media.

5. All translations not otherwise credited are my own.

6. When quoting others' work, I use the transliteration system originally chosen by other authors. 
This page intentionally left blank 


$$
\begin{gathered}
\text { K-Pop } \\
\text { Live }
\end{gathered}
$$


This page intentionally left blank 